\title{
Characterization of uterine leukocyte infiltration in gilts after artificial insemination
}

\author{
K. J. Rozeboom ${ }^{1}$, M. H. T. Troedsson ${ }^{2}$ and B. G. Crabo ${ }^{1}$ \\ ${ }^{1}$ Department of Animal Science and ${ }^{2}$ Clinical and Population Sciences, University of Minnesota, St Paul, MN 55108, USA
}

\begin{abstract}
The objective of this study was to characterize the uterine leukocyte influx after artificial insemination (AI). After detection of oestrus with a boar at intervals of $1.5 \mathrm{~h}$, seventytwo gilts were randomly assigned to a $2 \times 3 \times 4$ factorial arrangement. AI was performed with $100 \mathrm{ml}$ extended semen containing $5 \times 10^{9}$ spermatozoa (semen; $n=36$ ) or $100 \mathrm{ml}$ VSP semen extender (extender; $n=36$ ) at one of three times after detection of oestrus: 12,24 or $36 \mathrm{~h}$ ( $n=24 /$ time). The uterus was lavaged at $6,12,18$ or $24 \mathrm{~h}(n=$ 18 / time) after AI to determine the total number of uterine leukocytes. In addition, uterine lavage was performed on nine untreated gilts immediately after the detection of oestrus to establish a baseline number of leukocytes. The leukocyte response in all samples consisted predominately $(92-99 \%)$ of polymorphonuclear neutrophilic granulocytes (PMNs). The mean number of PMNs recovered from the uteri of gilts treated with semen was greater than in gilts treated with extender and in untreated gilts $(P<0.01)$. The greatest number of PMNs in semen-treated gilts was found $12 \mathrm{~h}$ after AI $(P<0.01)$, and this number was sustained for $24 \mathrm{~h}$. In contrast, the number of uterine PMNs recovered from extender-treated gilts reached a peak at $6 \mathrm{~h}$ and had declined by $12 \mathrm{~h}$ after AI $(P<0.05)$. It was concluded that an extensive influx of PMNs into the uterus is a normal sequence to AI. The consequences and importance of semen-induced uterine leukocytosis needs further investigation.
\end{abstract}

\section{Introduction}

A large volume of semen is deposited into the uterus of the sow during natural mating and artificial insemination; this also occurs in the mare, but in most other domestic animals vaginal deposit of semen occurs. The processes of uterine clearance after mating and insemination in the sow include physical clearance due to myometrial contractions and phagocytosis by neutrophilic granulocytes that enter the uterus within $2 \mathrm{~h}$ after insemination (Lovell and Getty, 1968; Pursel et al., 1978; Viring and Einarsson, 1981; Hunter, 1982; Rodriguez-Martinez et al., 1990). After mating, uterine inflammation may be important for preimplantation preparation of the uterus to ensure an optimal environment for embryo survival (Hunter, 1982).

Semen induces a neutrophilic response in the uterus of the mare after insemination (Kotilainen et al., 1994; Troedsson et al., 1995a; Katila, 1995). It appears that sperm-induced uterine inflammation is a normal physiological response in the mare and serves to clear the uterus from excess spermatozoa and contamination associated with mating (Troedsson, 1997).

We have shown that when the last of multiple inseminations in the pig is performed during late oestrus (i.e. after ovulation), a decrease in fertility can be expected (Rozeboom et al., 1997) and suggested that the lowered

Revised manuscript received 27 April 1998. fertility may be the result of persisting inflammatory products in the uterus. Although previous investigations have demonstrated that there is an influx of neutrophils into the uterus after insemination, this influx has not been quantified.

The objectives of this study were to characterize uterine inflammation in pigs after breeding and to determine the magnitude, response time, and duration of the inflammatory cellular response after AI.

\section{Materials and Methods}

\section{Animals}

A pool of 105 prepubertal 1/2 Hampshire, 1/4 Yorkshire, 1/4 Landrace gilts from the University of Minnesota swine herd was considered for this experiment. The first 72 gilts at oestrus were used in the factorial arrangement of this study. These gilts were 150-160 days of age at the start of the study and housed from June through September in a mechanically ventilated confinement gestation facility.

\section{Synchronization and detection of oestrus}

Oestrus was induced by injecting each female intramuscularly in the neck with 400 iu eCG and 200 iu hCG 
(Azko Intervet ${ }^{\circledR}$ PG600 $^{\circledR}$, Intervet Inc., Millsboro, DE) at 150-160 days of age. Eighteen days after the first synchronized oestrous cycle, oestrus detection was performed at intervals of $1.5 \mathrm{~h}$ until all females were either detected in oestrus or deemed non-cyclic (anoestrous). The first seventy-two gilts that were determined to be in oestrus were used in this study. Uterine lavage was performed on nine additional gilts immediately after being detected in oestrus to determine the number of PMNs that are present in the uterus before insemination. Oestrus detection was performed by allowing females nose to nose contact with a mature boar, and by applying back pressure. Females that exhibited a standing heat reflex were considered to be in oestrus.

\section{Semen collection and preparation}

Semen was collected from two boars of known fertility using the gloved hand technique and brought to the laboratory for evaluation of sperm concentration with a haemocytometer and motility subjectively under a light microscope. An equal volume of semen from each boar was diluted with VSP semen extender (IMV International, Minneapolis $\mathrm{MN}$ ) to form a dose of $100 \mathrm{ml}$ extended semen containing $5 \times 10^{9}$ spermatozoa. The extender contained $200 \mathrm{mg}$ of active gentamicin and $1 \times 10^{6}$ iu penicillin $\mathrm{l}^{-1}$ to minimise growth of bacteria.

\section{Experimental design}

After detection of oestrus, females were assigned to one of three insemination times for each treatment: $12 \mathrm{~h}(n=12)$, $24 \mathrm{~h}(n=12)$ or $36 \mathrm{~h}(n=12)$. Gilts were inseminated with extended semen $(n=36)$ or $100 \mathrm{ml}$ of semen extender alone $(n=36)$. Uterine lavage was performed at one of four different time intervals after each insemination, $6 \mathrm{~h}(n=3)$, $12 \mathrm{~h}(n=3), 18 \mathrm{~h}(n=3)$ or $24 \mathrm{~h}(n=3)$, to determine the total number of cells in the uterus. Each female was inseminated only once with either semen or extender, and lavaged once after insemination.

\section{Procedures at insemination}

After the detection of oestrus, and at the scheduled service time after the onset of oestrus, each gilt was separated from the group and detained in a pig handling room. After a thorough cleansing of the perineum and vulva with a diluted iodine surgical scrub (Betadine ${ }^{\circledR}$; The Perdue Frederick Company, Norwalk, CT), gilts were moved to a pen adjacent to a mature boar where they were allowed nose-to-nose contact while they were inseminated with the use of a Minitube ${ }^{\circledR}$ spirette (Minitube of America, Verona WI). Before insertion, the tip of the spirette was lubricated with a nonspermicidal sterile lubricating jelly (Priority Care ${ }^{\mathbb{E}}$; First Priority, Inc. Gilberts, IL). During insemination, back pressure was applied and the infusion content was allowed to be drawn into the uterus by gravity.

\section{Procedures during lavage}

Gilts were restrained in a single stall crate and washed as previously described. A sterile catheter consisting of a 'Golden Pig' catheter with an inner flexible, removable tubing with a small stainless steel ball placed on the end (Cryogolden Pig ${ }^{(B)}$; IMV International, Minneapolis MN) was inserted into the reproductive tract and locked into the cervix. The inner tubing of the catheter was manipulated through the cervix and $120-240 \mathrm{ml}$ phosphate-buffered saline (PBS) was infused into the uterine lumen. The volume of fluid used for lavage varied depending on each separate lavage procedure, to ensure that a sufficient amount of fluid was recovered (>15 ml). As much lavage fluid as possible was then collected during gravitational flow back through the larger catheter into a sterile glass flask.

\section{Laboratory procedures}

The volume of the recovered lavage fluid was measured and after thorough mixing, a $2 \mathrm{ml}$ aliquot from the initial sample was cultured for bacterial growth by layering the effluent over a blood agar plate. The cultures were incubated for $48 \mathrm{~h}$ at $37^{\circ} \mathrm{C}$. Bacterial growth was assessed by counting the colonies on each plate. The remainder of the lavage fluid was centrifuged at $400 \mathrm{~g}$ for $10 \mathrm{~min}$ and the supernatant was removed and discarded. The pellets were resuspended in $1 \mathrm{ml} \mathrm{PBS}$ and the number of leukocytes in each sample was counted in a haemocytometer after dilution 1:100 with a Unipet $^{(\mathbb{B}}$ (Becton-Dickinson, Rutherford, NJ). Microscope slides were stained using a Diff-Quik ${ }^{\circledR}$ stain set (Dade Diagnostics of P. R. Inc., Aguada, PR) for differential counting to determine the relative amounts of various types of leukocyte in each sample. After centrifugation and resuspension of the pellet, a $0.1 \mathrm{ml}$ aliquot from each lavage sample was smeared onto a glass microscope slide. The slide was dipped in sequence five times each in methyl alcohol (fixative), Eosin $Y$, and thiazine dyes. The slides were rinsed with distilled water and allowed to dry. Each sample was evaluated at $\times 1000$ magnification under oil immersion. One hundred cells from each sample were counted and the results were used to calculate the total number of various types of leukocyte in the lavage fluid.

\section{Statistical analysis}

Leukocytes were considered to be evenly distributed in the uterus. The recovered volume $(15-168 \mathrm{ml})$ was consistently less than the volume of PBS infused. The number of leukocytes determined in the recovered fluid was multiplied by the volume of PBS infused into the uterus and divided by the recovered volume to obtain the total number of leukocytes in the uterine lumen. This number was finally multiplied by the percentage of various types of leukocytes determined by differential counting to obtain the total number of PMNs and other types of leukocyte recovered from the uterine lumen.

Differential counts of all samples showed that $95 \pm 0.1 \%$ of 
all leukocytes recovered were PMNs. Statistical analysis was performed using only calculated numbers of PMNs from each sample because few other leukocyte types were present. The total number of uterine PMNs was transformed to their natural $\log$ value for statistical analysis using analysis of variance (ANOVA). Treatments (semen or extender), AI time after the onset of oestrus $(12,24$ or $36 \mathrm{~h}$ ), and lavage time following insemination $(6,12,18$ or $24 \mathrm{~h})$ were used in a $2 \times 3 \times 4$ factorial arrangement. Polynomial orthogonal contrasts were used to examine the effects of insemination time, lavage time, and their interactions with treatment on numbers of uterine PMNs. When interactions were present, Fisher's protected least significant differences were used to compare mean differences. One-way analysis of variance was used to examine treatment and baseline numbers of PMNs. Student's $t$ tests were used to compare sample volume, mean number of PMNs and $P$ values below 0.05 were considered significant. All data were analysed using the computer software SAS (1994).

\section{Results}

The volume of PBS infused into the uterus ranged from 120 to $240 \mathrm{ml}$ and the recovered lavage fluid ranged from 15 to 168 $\mathrm{ml}$, but was similar among treatment groups (Table 1). Furthermore, the portion of PMNs in the cellular part of the recovered fluid was similar for the two treatment groups but higher than the baseline value (Table $1, P<0.05$ ). The number of PMNs was not influenced by the volume of lavage fluid recovered in all of the treatment groups (Table 2 ).

Differential counts of cells for all samples showed that
$95 \pm 0.1 \%$ of the leukocytes in the lavage fluid were PMNs. Differential cell counts were not affected by treatment, insemination time, or flush time (Table 3). Although the percentage of PMNs decreased slightly over the $24 \mathrm{~h}$ period after AI, PMNs remained the primary inflammatory cell type throughout oestrus and after insemination. However, the fraction of leukocytes that consisted of PMNs in the uteri of baseline control gilts was lower than in treatment gilts $(P<0.05$; Table 1$)$.

Bacterial culture of semen consistently revealed growth of Streptococcus sp., Staphylococcus sp. and Pseudomonas sp., which are common semen contaminants (Waltz et al., 1968).

The mean number of uterine PMNs recovered from gilts inseminated with semen was higher than in females inseminated with extender alone and in baseline control gilts (Table $1 ; P<0.01$ ). Although higher numerically, the mean number of PMNs from the group of females treated with extender was not significantly different from the baseline value.

There was no interaction between treatment and AI time after the onset of oestrus $(P=0.63)$; therefore, numbers of PMNs after AI at 12, 24 or $36 \mathrm{~h}$ after the onset of oestrus for each treatment were pooled for analysis. The semen treatment caused a significant increase in the total number of uterine PMNs after AI at all times after the onset of oestrus compared with baseline values (Fig. $1 ; P<0.05$ ). Furthermore, infusion with extender alone resulted in an increased number of PMNs in the lavage fluid of gilts that were treated at $24 \mathrm{~h}$ after the onset of oestrus compared with baseline values (Fig. $1 ; P<0.05$ ), whereas treatment at 12 and $36 \mathrm{~h}$ after the onset of oestrus did not.

Table 1. The volume of lavage fluid, the volume of fluid recovered, polymorphonuclear neutrophilic granulocytes (PMNs) as a percentage of leukocytes, and the total number of PMNs recovered from gilts after insemination with $100 \mathrm{ml}$ of either extended semen $\left(5 \times 10^{9}\right.$ sperm cells $)$ or extender alone

\begin{tabular}{lccccc}
\hline Treatment & $n$ & $\begin{array}{c}\text { PBS infused } \\
(\mathrm{ml})\end{array}$ & $\begin{array}{c}\text { Fluid recovered } \\
(\mathrm{ml})\end{array}$ & Percentage PMNs & Total PMNs recovered $\left(10^{6}\right)$ \\
\hline $\begin{array}{l}\text { Semen } \\
\text { Extender }\end{array}$ & 36 & $191 \pm 13.9$ & $74.7 \pm 4.5$ & $95.9 \pm 0.03^{\mathrm{a}}$ & $40.2 \pm 9.3^{\mathrm{c}}$ \\
$\begin{array}{l}\text { Baseline } \\
\text { control }\end{array}$ & 9 & $181 \pm 13.6$ & $70.3 \pm 4.5$ & $95.6 \pm 0.1^{\mathrm{a}}$ & $11.2 \pm 4.4^{\mathrm{d}}$ \\
\hline
\end{tabular}

Values are means \pm SEM.

a,b Values in columns with different superscripts are significantly different $(P<0.05)$.

id Values in columns with different superscripts are significantly different $(P<0.01)$.

Table 2. The calculated mean number of uterine polymorphonuclear neutrophilic granulocytes (PMNs) present when less than or more than $50 \mathrm{ml}$ of lavage fluid was recovered from gilts after insemination with $100 \mathrm{ml}$ of extended semen $\left(5 \times 10^{9}\right.$ sperm cells), extender alone or without treatment (baseline)

\begin{tabular}{|c|c|c|c|c|c|c|}
\hline \multirow[b]{2}{*}{ Recovered sample volume (ml) } & \multicolumn{2}{|c|}{ Semen } & \multicolumn{2}{|c|}{ Extender } & \multicolumn{2}{|c|}{ Baseline } \\
\hline & $n$ & PMNs & $n$ & PMNs & $n$ & PMNs \\
\hline$<50 \mathrm{ml}$ & 7 & $40.6 \pm 16.7$ & 7 & $8.4 \pm 1.9$ & 2 & $3.9 \pm 1.5$ \\
\hline$>51 \mathrm{ml}$ & 29 & $40.0 \pm 11.0$ & 29 & $11.8 \pm 5.4$ & 7 & $3.2 \pm 1.6$ \\
\hline
\end{tabular}

Values are means $\left(\times 10^{6}\right) \pm$ SEM. 
Table 3. The number of polymorphonuclear neutrophilic granulocytes (PMNs) expressed as a percentage of the total number of non-epithelial cells recovered from the uteri of gilts after insemination with either extended semen $\left(5 \times 10^{9}\right.$ sperm cells $)$ or extender ${ }^{a}$

\begin{tabular}{|c|c|c|c|c|c|c|c|c|}
\hline \multirow[b]{3}{*}{ Treatment } & \multicolumn{8}{|c|}{ Percentage PMNs } \\
\hline & \multicolumn{3}{|c|}{ Insemination time } & \multicolumn{4}{|c|}{ Flush time } & \multirow[b]{2}{*}{ Total mean } \\
\hline & $12 \mathrm{~h}$ & $24 \mathrm{~h}$ & $36 \mathrm{~h}$ & $6 \mathrm{~h}$ & $12 \mathrm{~h}$ & $18 \mathrm{~h}$ & $24 \mathrm{~h}$ & \\
\hline Semen & $97 \pm 1$ & $95 \pm 2$ & $95 \pm 2$ & $99 \pm 0.3$ & $94 \pm 1$ & $97 \pm 0.3$ & $92 \pm 2$ & $96 \pm 0.3$ \\
\hline VSP & $97 \pm 2$ & $91 \pm 2$ & $98 \pm 3$ & $93 \pm 3$ & $99 \pm 3$ & $95 \pm 2$ & $95 \pm 3$ & $95 \pm 1$ \\
\hline Total mean & $97 \pm 1$ & $93 \pm 1$ & $97 \pm 1$ & $96 \pm 2$ & $97 \pm 1$ & $96 \pm 1$ & $93 \pm 2$ & \\
\hline
\end{tabular}

Values are means \pm SEM.

aVSP, IMV International, Minneapolis MN.

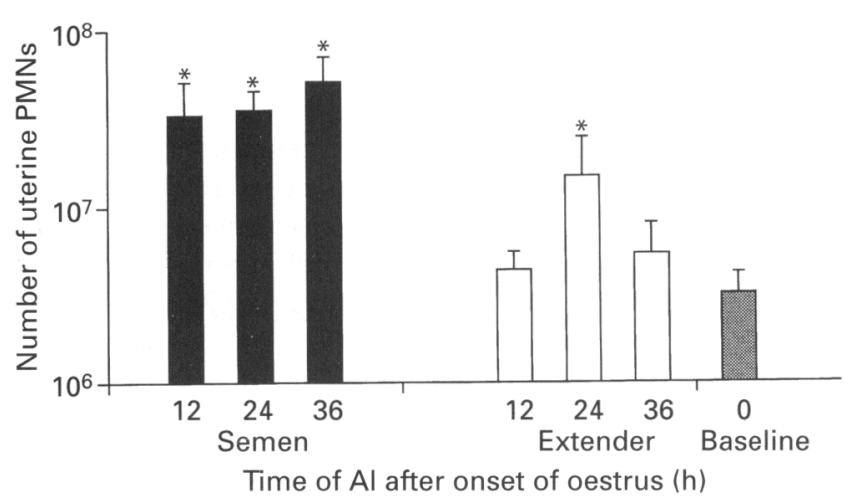

Fig. 1. The number of uterine polymorphonuclear neutrophilic granulocytes $(\mathrm{PMNs})$ (mean \pm SEM) recovered from gilts inseminated with extended semen ( $\mathbf{\square} ; n=12 /$ time; $5 \times 10^{9}$ sperm cells) or extender alone ( $\square ; n=12 /$ time) at 12,24 or $36 \mathrm{~h}$ after the onset of oestrus determined by averaging uterine lavage PMN numbers collected at $6,12,18$ and $24 \mathrm{~h}$ after insemination. Baseline uterine PMN numbers (圆) were collected by uterine lavage after the detection of oestrus in nine untreated gilts. Treatment by insemination time interaction was not significant for uterine PMN numbers $(P=0.63)$; therefore, mean comparisons among treatments were not made for time of $\mathrm{AI}$ relative to the onset of oestrus. Baseline and treatment mean numbers of PMNs were examined using oneway analysis of variance (treatment versus baseline, ${ }^{*} P<0.05$ )

The uterine PMN response to semen after insemination differed in both magnitude and duration compared with infusion with extender alone. This resulted in a significant interaction for lavage time after insemination $(P<0.01)$. A similar influx of PMNs had occurred by $6 \mathrm{~h}$ after insemination in gilts treated with both semen and extender (Fig. 2). While numbers of PMNs had fallen $(P<0.01)$ to baseline numbers at $12 \mathrm{~h}$ after infusion and remained at the baseline value thereafter in extender treated gilts, numbers of PMNs continued to increase in semen-treated gilts and reached peak values $12 \mathrm{~h}$ after insemination (Fig. $2 ; P<0.05$ ). The number of uterine PMNs had not significantly decreased in semen-treated gilts at $24 \mathrm{~h}$ compared with the initial response at $6 \mathrm{~h}$ (Fig. $2 ; P<0.05$ ).

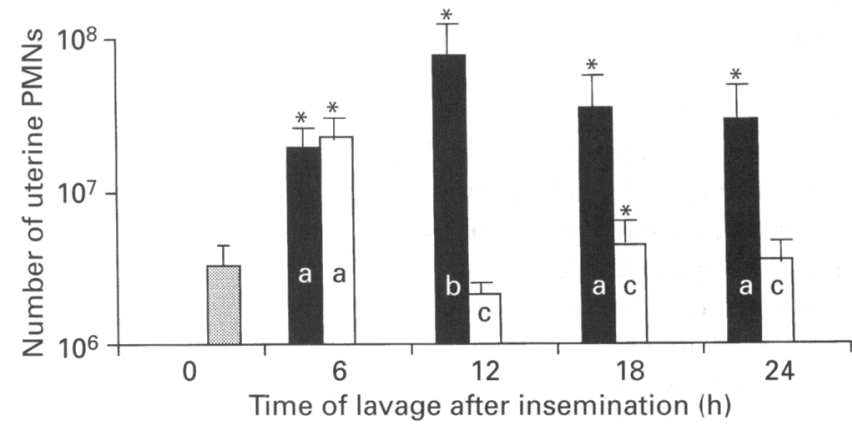

Fig. 2. The number of uterine polymorphonuclear neutrophilic granulocytes (PMNs) (mean \pm SEM) recovered from gilts infused with $100 \mathrm{ml}$ of either extended semen ( $\mathbb{\square} ; n=9 /$ time; $5 \times 10^{9}$ sperm cells) or extender alone $(\square ; n=9 /$ time $)$ at $6,12,18$ or $24 \mathrm{~h}$ after insemination. Baseline (圆) numbers of uterine PMNs were collected at the beginning of oestrus in nine untreated gilts. Gilts treated with semen had significantly more uterine PMNs recovered at 12,18 and $24 \mathrm{~h}$ after insemination compared with gilts treated with extender alone (a versus $b, P<0.05$; a versus $c, P<0.01$ ). Baseline and treatment mean numbers of PMNs were examined using one-way analysis of variance (treatment versus baseline, ${ }^{*} P<0.05$ ).

\section{Discussion}

The aim of this experiment was to characterize PMN migration into the uterus after artificial insemination. The use of non-surgical uterine lavage to recover PMNs from the uterus is a novel approach in pigs, but has previously been described in mares (Troedsson et al., 1995a). In contrast to horses, the uterus cannot be manipulated manually in gilts for full recovery of lavage fluid. This probably causes the variations between infused and recovered volumes in the present study. In spite of this, the volume of effluent fluid did not significantly affect the numbers of PMNs. The relative differences in numbers of PMNs between treatments should, therefore, reflect the number of PMNs in the uterus at the time of lavage.

A mixed bacterial flora was found in all uterine lavage samples with no differences detected between treatment 
groups (data not shown). It is reasonable to consider that the bacterial contamination occurred during the insemination procedure as well as during the collection of lavage fluid, since a sterile insemination is highly unlikely under practical insemination conditions. The presence of small numbers of bacteria in the uterine lavage makes it impossible to determine conclusively that the induced uterine inflammation in this study was caused by semen. However, the dissimilar uterine inflammatory response between extender and semen treatment implies that the inflammatory response was primarily a reaction to semen, since the bacterial contamination of all samples was similar and the extender was free from bacteria.

The similarities between the first influx of neutrophils $6 \mathrm{~h}$ after insemination in both treatments may have been associated with the insemination technique or the introduction of a mixed bacterial flora of vaginal origin into the uterus. The influx of PMNs in females treated with extender was short lived as can be expected since the extender contained no chemoattractive components. The presence of microbes, but more importantly spermatozoa, may explain the significant increase in numbers of PMN from AI with semen observed 12 compared with $6 \mathrm{~h}$ after AI. Equine spermatozoa, like bacteria, have been shown to effect PMN migration in mares by activating complement (Troedsson et al., 1995b). It appears from the studies of the uterine defence mechanisms of the mare (Troedsson et al., 1994) that semen-induced inflammation is physiological, serving to clear the uterus from excess spermatozoa, seminal plasma and bacterial contaminants. Thus it plays a critical role in providing an optimum uterine environment for embryo survival. In swine, these effects have not been investigated. Since the pig and the horse both have a large volume of semen deposited into the uterus (Hunter, 1991), it is possible that the migration of PMNs into the uterine lumen following insemination is a critical part of the uterine clearance mechanism for the sow as well.

Small numbers of PMNs were present in the uterus before treatment with either semen or extender. This finding is supported by previous reports in normally cyclic gilts in which uterine PMNs were commonly found during oestrus (Bischof et al., 1994). These authors suggested that increasing concentrations of oestrogens and an increased uterine blood flow during a stage of oestrus when the female is most likely to be exposed to foreign antigens may be responsible for the large numbers of PMNs. Although this observation may explain the presence of PMNs before insemination, the significant increase in PMN infiltration into the uterine lumen after insemination is likely to have been triggered by a chemotactic signal. Furthermore, the percentage of leukocytes determined as PMNs also increased significantly from pretreatment values, therefore, reflecting the role of PMNs as the dominant cell type in inflammation after breeding.

Although PMN numbers did not vary by insemination time after the onset of oestrus, it is important to consider that the PMN inflammation from semen persisted in the uterus for more than $24 \mathrm{~h}$ after AI. This may explain some of the lowered fertility observed when sows and gilts received the last of multiple inseminations during late oestrus (Rozeboom et al., 1997). The impact of a PMN environment on embryo viability has not been investigated, but it is quite possible that the presence of PMNs when embryos enter the uterus at 2 days after ovulation is detrimental for normal development and viability (Hunter, 1990).

In conclusion, infusion of semen into the uterus provoked a PMN influx in the gilt which was greater than after insemination with extender alone. This inflammatory response was temporally different between females inseminated with semen and females infused with extender alone. Inflammation after mating has been shown to play a critical role in the uterine defence mechanism of the mare, and since the mating mechanism is similar in the mare and the sow, it is possible that this is also the case in swine.

This paper is published as paper no. 971167701 of the scientific journal article series of the Minnesota Agriculture Experiment Station. The authors would like to thank the Minnesota Pork Producers Association for their financial support of this project.

\section{References}

Bischof RJ, Brandon MR and Lee C-S (1994) Studies on the distribution of immune cells in the uteri of prepubertal and cycling gilts fournal of Reproductive lmmunology 26 111-129

Hunter RHF (1982) Fertilization and embryonic development in the oviduct Reproduction of Farm Animals p 56 Longman Inc., London and New York

Hunter RHF (1990) Fertilization of pig eggs in vivo and in vitro. Journal of Reproduction and Fertility Supplement 40 211-226

Hunter RHF (1991) Fertilization in the pig and the horse A Comparative Overview of Mammalian Fertilization pp 329-349 Eds BS Dunbar and MG O'Rand. Plenum Press, New York

Katila T (1995) Onset and duration of uterine inflammatory response of mares after insemination with fresh semen Biology of Reproduction Monograph 1: Equine Reproduction VI 515-517

Kotilainen T, Huhtinen M and Katila T (1994) Sperm-induced leukocytosis in the equine uterus Theriogenology $41629-636$

Lovell JE and Getty $\mathbf{R}$ (1968) Fate of semen in the uterus of the sow: histological study of endometrium during the 27 hours after natural services American Journal of Veterinary Research 29 609-625

Pursel VG, Schulman LL and Johnson LA (1978) Distribution and morphology of fresh and frozen-thawed sperm in the reproductive tract of gilts after artificial insemination Biology of Reproduction 19 69-76

Rodriguez-Martinez $H$, Nicander L, Viring S, Einarsson $S$ and Larsson $K$ (1990) Ultrastructure of the utero-tubal junction in pre-ovulatory pigs Anatomy Histology and Embryology 19 16-36

Rozeboom KJR, Troedsson MHT, Shurson GC, Hawton JD and Crabo BG (1997) Late estrus or metestrus insemination subsequent to estrual inseminations decreases farrowing rate and litter size in swine Journal of Animal Science 75 2323-2327

SAS (1994) SAS/STAT User's Guide (Release 6.10) SAS Institute Inc., Cary NC

Troedsson MHT (1997) Therapeutic consideration for mating-induced endometritis Pferdeheilkunde 13 516-520

Troedsson MHT, Liu IKM and Crabo BG (1994) Uterine defense mechanisms in the mare Archives of STD/HIV Research 8 259-269

Troedsson MHT, Crabo BG, Ibrahim NM, Scott M and Ing M (1995a) Mating-induced endometritis (MIE): mechanism, clinical importance, and consequences Proceedings of the American Association of Equine Practitioners 41 11-12

Troedsson MHT, Steiger BN, Ibrahim NM, Foster DN and Crabo BG (1995b) Mechanism of sperm-induced endometritis in the mare Biology of Reproduction 52 (Supplement 1) 91 (Abstract)

Viring S and Einarsson S (1981) Sperm distribution within the genital tract of naturally inseminated gilts Nordisk Veterinaermedicin 33 145-149

Waltz FA, Foley CW, Herschler RC, Tiffany LW and Liska BJ (1968) Bacteriological studies of boar semen Journal of Animal Science 27 1357-1362 